\title{
Alignment errors to both ends of acute- and obtuse-angle arms
}

\author{
PETER WENDEROTH, HELEN BEH, and DENNIS WHITE \\ University of Sydney, Sydney, Australia 2006
}

\begin{abstract}
It has been reported that errors which occur in attempts to align the arms of two acute angles differ in size and direction from errors which occur when the angles are obtuse (Restle, 1969). Other experiments have qualified this conclusion, and it has been suggested that Restle's result was dependent on the use of a forced-choice method with a dual-angle display (Day, 1973). Data are reported here on dot-to-line misalignments using staircase techniques both at the free end and at the vertex end of single acute or obtuse angles. The results essentially agree with Day's method-of-adjustment results, thus implicating the display rather than the method as the cause of the original negative acute-angle effect. However, Day found no difference between the acute-angle effect and the parallelless Poggendorff illusion, while we did obtain a difference under some conditions. Consideration of the magnitudes and directions of errors at both ends of the angles' arms gives pause to any possible accounts of the errors in terms of simple or single whole-of-line effects.
\end{abstract}

Observers typically make errors when they attempt to align a dot either to the apparent extension of an isolated line segment or to a line segment which abuts another inducing line. Although these are general findings, the theoretical significance of such errors is not clear. For example, alignment errors to isolated lines have been interpreted as measuring differences between objective and perceived line orientation (Bouma \& Andriessen, 1968), vernier acuity (Matin, 1972), the parallelless Poggendorff illusion (Curthoys, Wenderoth, \& Harris, 1975), and the horizontalvertical illusion (Day \& Dickinson, 1976). In addition, alignment errors to one of two abutting lines have been described as measuring both induced line tilt effects (Bouma \& Andriessen, 1970; Matin, 1974; O'Toole \& Wenderoth, 1977) and Poggendorff illusions (Day \& Dickinson, 1976; Tong \& Weintraub, 1974), yet the latter effects appear not to be explicable entirely or even largely in terms of induced tilt effects (Hotopf \& Ollerearnshaw, 1972a, 1972b; Hotopf, Ollerearnshaw, \& Brown, 1974; Tong \& Weintraub, 1974; Day \& Dickinson, 1976). In short, errors which occur with essentially identical stimulus displays have been interpreted quite differently, depending upon the theoretical contexts within which the various experiments have been conducted.

With the aim of elucidating the nature of such line-dot alignment errors, Wenderoth, Beh, and White (1978) measured alignment errors at both ends of an

This project was supported by the Australian Research Grants Committee in 1975 and 1977. Peripherals and software for the display facilities were developed by Mike Cooper, Alan Parkinson, and John Holden; and Phil Greenwood and Margie Morgan assisted in collecting the data. oblique line segment as a function of line-dot separation.

A $2^{\circ} 6^{\prime}$ oblique test line (AB in Figure $1, \theta=45^{\circ}$ ) was presented either alone (control condition) or simultaneously with a vertical, inducing line (CD in Figure 1, experimental condition). On each trial, only one dot appeared with the line display and the observer judged whether the dot appeared above or below the test line's extension. A point of subjective alignment was measured at each of 10 horizontal coordinates ( 1 to 10 in Figure 1) using a double ran-

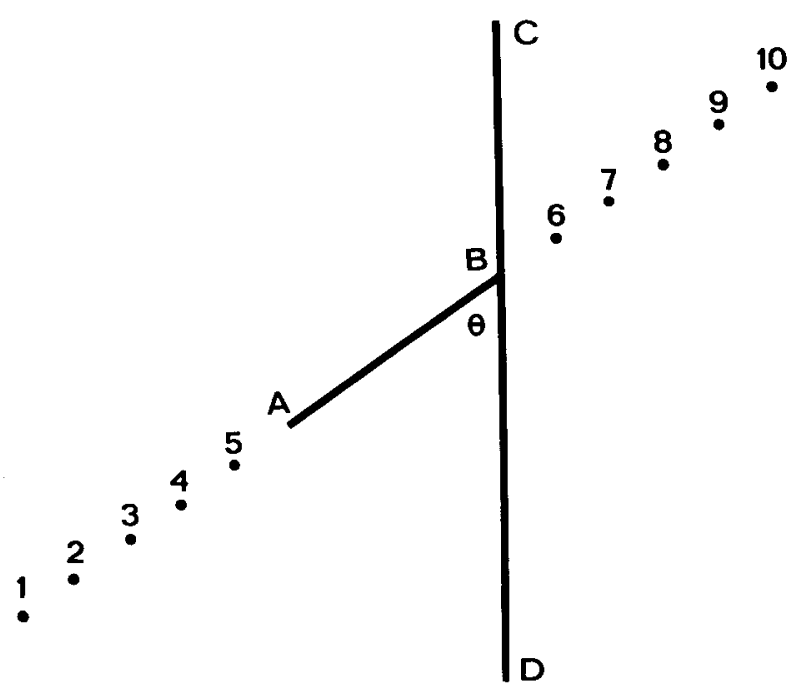

Figure 1. Schematic representation of display. (For obtuse-angle displays, only segment $\mathrm{CB}$ of $\mathrm{CD}$ was present, whereas only segment BD was present in acute-angle displays. In the control condition, $C D$ was absent. On each a trial, a single dot appeared. Only Positions $1,3,5,6,8$, and 10 were used.) 
domly interleaved staircase technique (e.g., Wetherill \& Levitt, 1965).

In the absence of $C D$, errors increased linearly as a function of line-dot separation at both ends of the test line. Since these errors extrapolated to zero close to the nearest test line extremity, the mean errors could be expressed as angular deviations from A or B. At each end, the mean point of subjective alignment differed from objective alignment by about $2^{\circ}$ to $3^{\circ}$. The dots were set too low in Positions 6 to 10 and too high in Positions 1 to 5 . When the inducing line CD was added, the errors at the "free" end (A) increased in the same direction, but only by about $0.5^{\circ}$; those at the "intersect" end (B) increased by $6^{\circ}$ or so. The fact that $C D$ induced unequal increments at the two ends, as well as the failure of the error functions to extrapolate to a common pivot either within or at one end of $A B$, provided strong evidence against any simple interpretation of the errors in terms of whole-line shift in perceived tilt of the test line.

We considered that the alignment paradigm schematically represented in Figure 1 might help to provide data to account for some of the more controversial findings in experiments on the Poggendorff illusion, in particular the so-called reversed acuteangle effect. According to Restle (1969), and others listed by Day (1973), the usual Poggendorff illusion is such that the upper-right transversal appears above the extension of the lower transversal (Figure 2A), and this is also true in the oblique-angled amputation (Figure 2B). However, Restle noted that the opposite is the case in the acute-angled version (Figure $2 \mathrm{C}$ ) in which the upper transverse segment appears too low.

A series of five experiments led Day (1973) to challenge the generality of this finding. He found that when the method of adjustment was used, mean acute-angle effects were always positive or zero, although smaller effects occurred with the $30^{\circ}$ angle used by Restle than with the $45^{\circ}$ angle more commonly used by himself. Day also found that the $45^{\circ}$ acute-angle effect did not differ from the parallelless effect (transverse segments only) indicating little or no contribution of the acute angle to the illusion. However, when a forced-choice psychophysical method was employed with the $45^{\circ}$ acute-angle figure, Day obtained a negative illusion, as Restle had done when he used the $30^{\circ}$ figure, also with a forcedchoice technique. Day suggested that this surprising difference due to psychophysical method might have occurred because the forced-choice method somehow caused the observer to judge the relative directions in which the arrowheads (i.e., acute-angle bisectors) were pointing (Figure $2 \mathrm{C}$ ), rather than the relative alignments of the transverse segments.

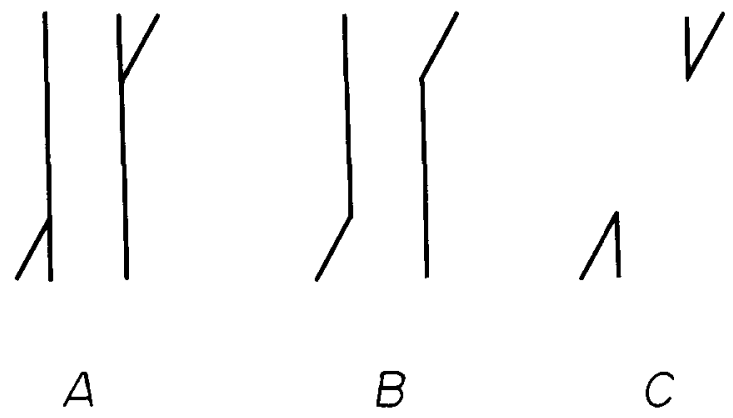

Figure 2. Variants of the Poggendorff illusion with $30^{\circ}$ transverse segments and vertical inducing lines. (A) complete figure, (B) obtuse-angle variant, and $(C)$ acute-angle variant.

The paradigm summarized in Figure 1 seemed especially suited to explore acute- and obtuse-angled Poggendorff effects, because the Poggendorff effect is either unchanged or only slightly reduced when the right-hand parallel is omitted and the upper-right transverse segment is replaced by a dot (Tong \& Weintraub, 1974; Weintraub \& Krantz, 1971) and because the removal of one of the two acute angles (in Figure 2C) eliminates any possibility of arrowhead alignment (although the dot could still, in principle, be aligned with the angle bisector). The purpose of this experiment, then, was to measure acuteangle effects and obtuse-angle effects using the kind of display represented in Figure 1 with the forcedchoice technique described earlier in relation to Figure 1.

\section{METHOD}

\section{Apparatus}

General. A PDP-11/20 computer was interfaced with an Alpha 16 minicomputer to produce visual displays on the flat face of a Tektronix 604 display monitor (P4 phosphor). The display was viewed in the dark, and during the experiment the glare from the screen was negligible; the edges of the screen were only dimly visible after dark adaptation. The observer was seated $540 \mathrm{~mm}$ from the display with the head upright and eyes level with the center of the display; this position was maintained by a dental cement bite bar.

Visual display. The visual display can be described in relation to Figure 1. The test line (AB), inducing line segment $(\mathrm{CB}$ or BD), and dots $(1,3,5,6,8$ or 10$)$ all had a luminance (L) of $1.37 \mathrm{~cd} / \mathrm{m}^{2}$. Dot Positions 2, 4, 7, and 9 were not used in this experiment. The background screen luminance was not measurable using an SEI photometer but was considerably less than $.03 \mathrm{~cd} / \mathrm{m}^{2}$, the lower limit of the photometer. Thus, contrast of the stimulus elements, defined as $\left(\mathrm{L}_{\max }-\mathrm{L}_{\text {min }}\right) /\left(\mathrm{L}_{\max }+\mathrm{L}_{\min }\right)$, exceeded 0.95 .

The test line, $\mathrm{AB}$, in Figure 1, was oriented either $75^{\circ}$ or $45^{\circ}$ in these experiments, and the inducing line segment, $\mathrm{CB}$ or $\mathrm{BD}$, when present, was vertical $\left(90^{\circ}\right)$. Hence, $\theta$ was either $15^{\circ}$ or $45^{\circ}$. Dots 1,3 , and 5 (which were never presented simultaneously) were, respectively, 25,15 , and $5 \mathrm{~mm}$ from the free end, $\mathrm{A}$, of the test line. Similarly, Dots 6,8 , and 10 were, respectively, 5,15 , and $25 \mathrm{~mm}$ from $\mathrm{B}$, when aligned with $\mathrm{AB}$ and measuring along the $A B$ axis. These distances, in terms of visual angle sub- 
tended at the observer's eye, were $0.53^{\circ}(5 \mathrm{~mm}), 1.59^{\circ}$, and $2.65^{\circ}$. The other stimulus dimensions, in both linear and visual angle terms were as follows. All line widths and dot diameters were $0.3 \mathrm{~mm}\left(0.03^{\circ}\right)$. The length of $\mathrm{CB}$ was $40 \mathrm{~mm}\left(4.24^{\circ}\right)$, BD was $60 \mathrm{~mm}$ long $\left(6.36^{\circ}\right)$, and $\mathrm{AB}$ was $19.8 \mathrm{~mm}$ long $\left(2.10^{\circ}\right)$. The display screen was $13.93^{\circ}$ wide and $11.27^{\circ}$ high.

Response box. The observer was provided with a box on which two microswitches were mounted, one above the other. If a dot appeared to be too high, above the extension of $A B$, the observer pressed the upper switch; pressing the lower switch indicated that the dot looked too low. Each response caused the display to disappear for $1 \mathrm{sec}$.

\section{Procedure}

Test sessions lasted about $40 \mathrm{~min}$. The observer was seated before the display, a bite bar was made, and the following instructions were given: "In this experiment your task is to judge whether a dot looks aligned with the extension of an oblique line. The basic figure we use is like this ( $\mathrm{AB}$ plus dot, $\mathrm{CB}$ or $\mathrm{BD}$ absent) or like this (CB or BD present). The position of the dot will vary, sometimes appearing on one side and sometimes on the other. In all cases, you are to judge whether or not the dot lies on the imaginary extension of the oblique line, that is you have to judge where the dot looks to be in relation to this line [Experimenter shows $\mathrm{AB}$ only with dashed extension and arrows pointing 'too high' and 'too low']. If you think that the dot is too high to be lined up, press this button which is marked 'too high' and is uppermost on the box; if you think that it is too low press this button. Remember that the top one is 'too high' and the bottom one is 'too low': if you forget or get confused just ask me. You cannot say that the dot is lined up; you must make one or the other of these choices. Sometimes you will feel that you are guessing: don't worry about that, just make the best possible guess that you can." The observers were additionally instructed not to be concerned if a consecutive series of dots appeared all too high or too low. Accuracy was stressed and short rests were permitted whenever the subject desired them.

No instructions were given about fixation so that completely free inspection was permitted. In other experiments, using the complete inducing line $C D$, we have obtained identical results whether the observer fixated point B or freely inspected the display. Effects similar to those obtained by Prytulak (1973a, 1973b) can be induced with fixation above or below B, but these are factored out in experimental-minus-control data and are discussed elsewhere (Wenderoth, White, \& Beh, Note 1).

Each subject completed two conditions, a control in which line segment CB or line segment BD was absent and an experimental condition in which $\mathrm{CB}$ or $\mathrm{BD}$ was present. These two conditions were given in random order and the total session lasted $30-40 \mathrm{~min}$.

Psychophysical method. Within either the experimental or control condition, a point of subjective alignment was found along an imaginary line passing through each dot and parallel to $\mathrm{CB}$ or $\mathrm{BD}$, using a double, randomly interleaved staircase method, adapted from Cornsweet (1962) and from Wetherill and Levitt (1965). Consider just one of the dots in Figure 1, for example
Dot 6. When the subject first saw a dot with this horizontal coordinate, it was physically aligned with $\mathrm{AB}$, as in Figure 1. If the response was "too high," Dot 6 was moved vertically downwards by one increment when it was next presented in that staircase. In each randomly interleaved staircase, trials continued with a step size of $1 \mathrm{~mm}$ until four reversals had occurred; the mean point of subjective alignment was then calculated by the computer, the step size was halved to $0.5 \mathrm{~mm}$, and the staircase continued until eight new reversals had occurred, after which trials at this horizontal position were terminated.

All trials at one horizontal position were not run consecutively: not only were double randomly interleaved staircases run at each of the six horizontal locations $(1,3,5,6,8$, and 10) in Figure 1, but the computer was also programmed randomly to jump from one to another of these six locations, from trial to trial. This was done to avoid any perceived (or even implied) vertical path for the dot; so far as the observer was concerned, the dot location from trial to trial was random in both its horizontal and vertical coordinates.

At each of the six locations, the point of subjective alignment was estimated by taking the mean of the vertical coordinates for the last eight reversals. These means were calculated in units of dots on the screen and were later converted to errors in millimeters (10 dots per millimeter) or degrees of displacement.

\section{Subjects}

Thirty-two volunteers from an introductory psychology course, 12 males and 20 females aged between 19 and 23 , served as subjects in return for nominal course credit. All had emmetropic or corrected vision. Each subject was tested either with $\theta=15^{\circ}$ or $\theta=45^{\circ}$, and with either the obtuse-angle (inducing segment $\mathrm{CB}$ ) or acute-angle variant (inducing segment $\mathrm{BD}$ ). This resulted in four groups of eight subjects each, and each observer was randomly assigned to a group on arrival at the laboratory.

\section{RESULTS}

The results obtained in the control conditions with line segment CB or line segment BD absent will be considered first, followed by the corrected experimentalminus-control results.

\section{Control Conditions}

The mean errors in millimeters and associated standard errors are shown in Table 1. The means were obtained by averaging the errors at each end of the line over the three dot separations. Table 1 also shows the equivalent angular errors calculated using the mean line-dot separation of $15 \mathrm{~mm}$ and assuming that the nearest line tip is the origin of the errors (see below). The overall mean errors, averaging over

Table 1

Mean Misalignments, Standard Errors, and Equivalent Angular Errors (in Degrees) for Control Conditions

\begin{tabular}{|c|c|c|c|c|c|c|c|c|}
\hline & \multicolumn{4}{|c|}{ Free End of Test Line } & \multicolumn{4}{|c|}{ Intersect End of Test Line } \\
\hline & \multicolumn{2}{|c|}{$15 \mathrm{deg}$} & \multicolumn{2}{|c|}{$45 \mathrm{deg}$} & \multicolumn{2}{|c|}{$15 \mathrm{deg}$} & \multicolumn{2}{|c|}{$45 \mathrm{deg}$} \\
\hline & Acute & Obtuse & Acute & Obtuse & Acute & Obtuse & Acute & Obtuse \\
\hline $\begin{array}{l}\text { Mean* } \\
\text { SE } \\
\text { deg }\end{array}$ & $\begin{array}{r}-.79 \\
.30 \\
-.82 \\
\end{array}$ & $\begin{array}{r}-.34 \\
.35 \\
-.34 \\
\end{array}$ & $\begin{array}{r}-1.43 \\
.14 \\
-4.13 \\
\end{array}$ & $\begin{array}{r}-1.25 \\
.19 \\
-3.58\end{array}$ & $\begin{array}{r}+.85 \\
.18 \\
+.89\end{array}$ & $\begin{array}{r}+.05 \\
.39 \\
+.05\end{array}$ & $\begin{array}{r}+.76 \\
.22 \\
+2.14\end{array}$ & $\begin{array}{r}.76 \\
.31 \\
+2.12\end{array}$ \\
\hline
\end{tabular}

Note-Four groups of subjects, $N=8$ for each group.

*Positive errors refer to settings which are too low, negative errors to settings which are too high. 


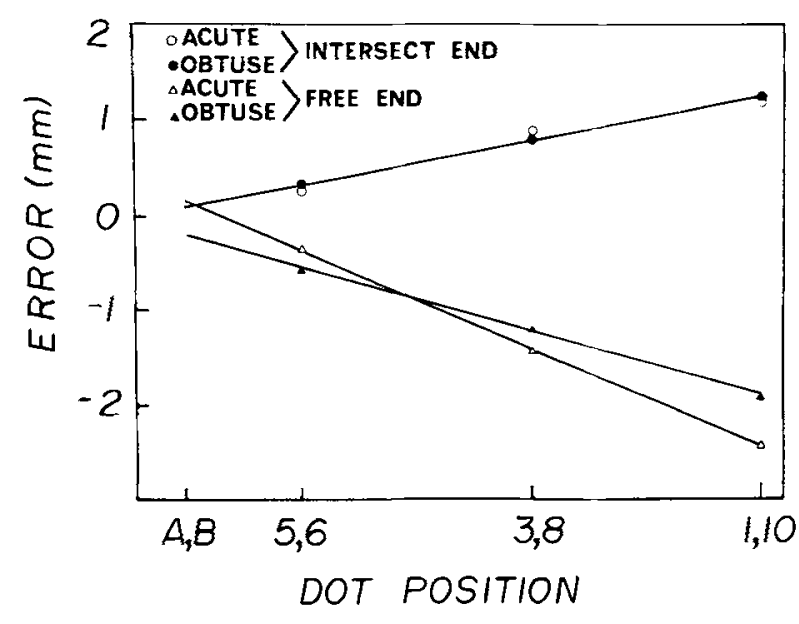

Figure 3. Mean vertical dot alignment errors for $\theta=45^{\circ}$ control conditions. Positive errors indicate dot settings which were too low.

the "acute" and "obtuse" groups at $45^{\circ}$, were $-3.86^{\circ}$ at the free end and $+2.13^{\circ}$ at the intersect end; these means are similar to those obtained by Wenderoth et al. (1978) under identical conditions $\left(-3.25^{\circ}\right.$ and $+2.28^{\circ}$, respectively). It is interesting to note that the overall mean errors in the $15^{\circ}$ groups were $-0.59^{\circ}$ and $+0.47^{\circ}$ at the free and intersect ends, respectively, so that these errors were smaller but in the same direction as those at $45^{\circ}$. These data are not consistent, therefore, with those of Bouma and Andriessen (1968), who claimed that alignment errors reflected perceived line tilt and who concluded that lines were perceptually attracted to the nearest main axis of space: on that hypothesis, no error would be expected at $45^{\circ}$ and errors opposite to those obtained here would be expected at $15^{\circ}$. However, our stimuli were continuously exposed, rather than flashed as were those of Bouma and Andriessen; perhaps this accounts for the difference.

Prior to averaging over the three dot separations, the data were analyzed by a one-way analysis of variance (Winer, 1962, Chap. 4). For each of the four groups, the variance was partitioned into linear and quadratic trend components at the free end and at the intersect end separately (four contrasts) and the one remaining orthogonal contrast tested the difference between the mean errors at the free and the intersect ends, taking account of algebraic sign. In all cases, the critical value of $F$ was $F(1,35)=4.12$, $\mathrm{p}=.05$.

None of the trend components was significant in the $15^{\circ}$ groups. In the $45^{\circ}$ groups (Figure 3), all linear trends were significant, $F=46.5,9.3,10.6$, and 4.8 for acute-free end, acute-intersect end, obtuse-free end, and obtuse-intersect end conditions, respectively, but no quadratic components were significant. Again, these results at $45^{\circ}$ replicate those of Wenderoth et al. (1978). Because the inducing line, $\mathrm{CB}$ or $\mathrm{BD}$, was absent in these control conditions, "acute" and "obtuse" groups were identical and the results were expected to be the same. That this was so in the $45^{\circ}$ conditions is evident from Figure 3.

The overall mean errors at the free and intersect ends (Table 1) were different from each other in the $15^{\circ}$ acute group, $F=41.2$, but not in the $15^{\circ}$ obtuse group, $F=1.26$. These means were different in both of the $45^{\circ}$ groups, $F=156.89$ and 71.35 , respectively.

The sixth comparison, which was not itself a contrast, determined whether the overall mean errors in each group were significant, i.e., whether the absolute magnitude of the errors at the free and the intersect ends were different. This was the case in the $45^{\circ}$ acute group, $F=14.45$, where the grand mean was $-1.00^{\circ}$ and in the $45^{\circ}$ obtuse group, $F=4.27$, where the mean was $-0.73^{\circ}$; but the overall means were not significant in the $15^{\circ}$ acute and obtuse groups, where the respective means were $+0.04^{\circ}$ and $-0.15^{\circ}$. This occasional occurrence of a larger absolute effect at the lower end of a line reflects what Tong and Weintraub (1974) called the "elevator effect," which they described as a propensity to set any dot too high.

The best-fit lines (Rodger, 1956, p. 60) to the error means in the $45^{\circ}$ conditions are shown in Figure 3. In each case, the extrapolated linear functions intersected the test line, $\mathrm{AB}$, less than $4 \mathrm{~mm}$ from each extremity of its total $19.8 \mathrm{~mm}$ length. It was on the assumption that these intercepts were sufficiently close to zero that errors were converted to angular effects (see above).

\section{Experimental Conditions}

The effect of introducing the relevant segment of line $\mathrm{CD}$ (CB in the obtuse condition and $\mathrm{BD}$ in the acute condition) was estimated by analyzing the difference between alignment errors in the experimental and control conditions.

Figures 4 and 5 show the mean difference measures at each dot position. Figure 4 shows the $15^{\circ}$ acute and obtuse data, while Figure 5 gives the result of the $45^{\circ}$ groups. For comparison purposes, and also to give some idea of the error variance, Table 2 shows the uncorrected experimental condition mean misalignments and standard errors. The standard errors generally increased as a function of line-dot separation, a result which would be expected if errors are constant angular effects.

The difference data were analyzed by the same methods as those described for the control data. Again, the critical $F$ value was $F(1,35)=4.12$, $p=.05$. Considering the tests of trend, only four of the linear trends were significant, those for $15^{\circ}$ obtuse, free-end and intersect-end conditions, 


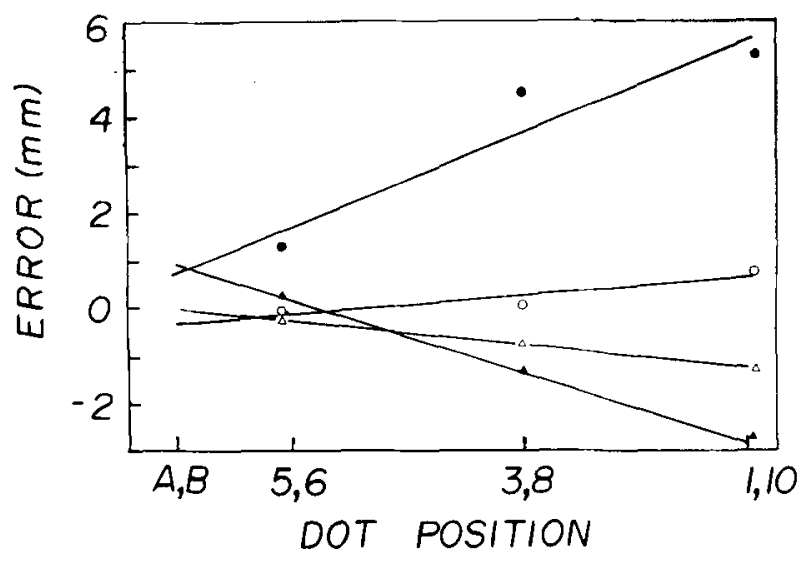

Figure 4. As for Figure 3, with $\theta=15^{\circ}$, but for experimentalminus-control data. Symbols as in Figure 3.

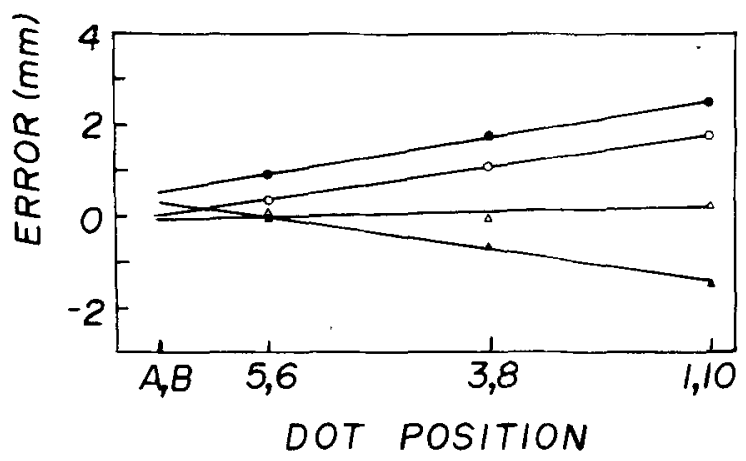

Figure 5. As for Figure 4, but with $\theta=45^{\circ}$. Symbols as in Figure 3.

$F=17.04$ and 31.29 , respectively, and those for the $45^{\circ}$ acute and obtuse intersect-end conditions, $F=23.98$ and 4.13 , respectively. None of the quadratic trends was significant.

Partly because the linear sums of squares were large enough to produce near-significant values in other conditions (e.g., $45^{\circ}$ obtuse, free end, $F=3.32$ ) and partly to obtain estimates of the intercepts, bestfit lines were calculated for all the data and are shown in Figures 4 and 5 , where it can be seen that reasonably good fits were obtained in all conditions. The intercepts extrapolated from the linear functions ranged from +9.51 to $-6.63 \mathrm{~mm}$, and hence it might have been unreasonable to assume that each of the three points of subjective alignment, at each end of the test line, estimated a fixed angular deviation from the line end. That is, the assumption that the true linear intercept is zero might be questionable. For that reason, the three mean dot misalignments at each end of the test line were averaged but are presented in Table 3 both in terms of mean displacement in millimeters and also in terms of angular displacement.
The angular values were calculated for each subject prior to averaging from the formula

$$
\alpha=(90-\theta)-\tan ^{-1}[\tan (90-\theta)-\mathrm{d} / \mathrm{w}] .
$$

where $\theta$ is the angle between the test line and the inducing line (Figure 1), $d$ is the mean alignment error in millimeters, and $w$ is the horizontal separation between the end of the test line and the middle dot ( 3 or 8 in Figure 1). Thus, for example, when the orientation $(\theta)$ of $\mathrm{AB}$ is $15^{\circ}, \mathrm{w}$ is $3.882 \mathrm{~mm}$; and when $\theta$ is $45^{\circ}, w$ is $10.607 \mathrm{~mm}$. Hence, if the vertical misalignment is, say, $2 \mathrm{~mm}$, then $\alpha$ for $\theta=15^{\circ}$ is $2.27^{\circ}$, whereas for $\theta=45^{\circ}$ the value of $\alpha$ is $5.94^{\circ}$.

A three-way analysis of variance, with repeated measures on one factor (free vs. intersect end) was carried out on the angular data of Table 3 (Winer, 1962 , p. 337). The critical $F$ value for all tests was $F(1,28)=4.20, p=.05$. The effect of test-line end, free vs. intersect, was significant, $F=24.27$, as was the Test-Line End by Acute/Obtuse interaction, $F=7.51$. The main effect reflects the fact that errors were towards the horizontal at both ends: overall negative errors at the free end $\left(-1.19^{\circ}\right)$ and positive errors at the intersect end $\left(+3.71^{\circ}\right)$. The interaction occurred because obtuse-angle errors were larger than acute-angle errors at the free end $\left(-2.00^{\circ}\right.$ vs. $\left.-0.38^{\circ}\right)$ and also at the intersect end $\left(+5.94^{\circ}\right.$ vs. $\left.+1.80^{\circ}\right)$.

None of the other main effects or interactions was significant. Presumably, a more sensitive test of the overall acute- vs. obtuse-angle main effect $\left(+0.71^{\circ}\right.$ vs. $+1.81^{\circ}$ ) would have been required to detect any between-subjects effect, $F(1,28)=3.18, p>.05$. For the angle-size main effect and the angle-size interaction with the oblique-obtuse conditions, the respective $F$ values were 2.98 and 2.00 . The $F$ values for the line-end vs. angle-size interaction and for

Table 2

Mean Misalignments (in Millimeters) and Standard Errors Obtained for Each Line-Dot Separation in the Experimental Conditions

\begin{tabular}{|c|c|c|c|c|c|c|c|}
\hline \multirow[b]{2}{*}{ Group* } & & \multicolumn{6}{|c|}{ Dot Position ** } \\
\hline & & 1 & 3 & 5 & 6 & 8 & 10 \\
\hline $\begin{array}{l}\text { 15-deg } \\
\text { Acute Angle }\end{array}$ & $\begin{array}{l}\text { Mean } \\
\text { SE }\end{array}$ & $\begin{array}{r}-2.17 \\
.51\end{array}$ & $\begin{array}{r}-1.73 \\
.33\end{array}$ & $\begin{array}{r}-.83 \\
.10\end{array}$ & $\begin{array}{r}+.63 \\
.13\end{array}$ & $\begin{array}{r}+.88 \\
.53\end{array}$ & $\begin{array}{r}+1.80 \\
.71\end{array}$ \\
\hline $\begin{array}{l}\text { 15-deg } \\
\text { Obtuse Angle }\end{array}$ & $\begin{array}{l}\text { Mean } \\
\text { SE }\end{array}$ & $\begin{array}{r}-3.20 \\
.74\end{array}$ & $\begin{array}{r}-1.85 \\
.44\end{array}$ & $\begin{array}{r}+.10 \\
.57\end{array}$ & $\begin{array}{r}+1.58 \\
.48\end{array}$ & $\begin{array}{r}+4.68 \\
.48\end{array}$ & $\begin{array}{r}+4.89 \\
.71\end{array}$ \\
\hline $\begin{array}{l}\text { 45-deg } \\
\text { Acute Angle }\end{array}$ & $\begin{array}{l}\text { Mean } \\
\text { SE }\end{array}$ & $\begin{array}{r}-2.25 \\
.30\end{array}$ & $\begin{array}{r}-1.51 \\
.21\end{array}$ & $\begin{array}{r}-.37 \\
.08\end{array}$ & $\begin{array}{r}+.58 \\
.09\end{array}$ & $\begin{array}{r}+1.95 \\
.20\end{array}$ & $\begin{array}{r}+2.96 \\
.24\end{array}$ \\
\hline $\begin{array}{l}\text { 45-deg } \\
\text { Obtuse Angle }\end{array}$ & $\begin{array}{l}\text { Mean } \\
\text { SE }\end{array}$ & $\begin{array}{r}-3.42 \\
.51\end{array}$ & $\begin{array}{r}-1.92 \\
.29\end{array}$ & $\begin{array}{r}-.66 \\
.15\end{array}$ & $\begin{array}{r}+1.21 \\
.36\end{array}$ & $\begin{array}{r}+2.53 \\
.85\end{array}$ & $\begin{array}{r}+3.70 \\
1.30\end{array}$ \\
\hline
\end{tabular}

${ }^{*} N=8$ for each group.

**As shown in Figure 1. 
Table 3

Mean Errors for Experimental Minus Control Conditions

\begin{tabular}{|c|c|c|c|c|c|c|c|c|}
\hline & \multicolumn{4}{|c|}{ Acute Angle } & \multicolumn{4}{|c|}{ Obtuse Angle } \\
\hline & \multicolumn{2}{|c|}{ Free End } & \multicolumn{2}{|c|}{ Intersect End } & \multicolumn{2}{|c|}{ Free End } & \multicolumn{2}{|c|}{ Intersect End } \\
\hline & $15 \mathrm{deg}$ & $45 \mathrm{deg}$ & $15 \mathrm{deg}$ & $45 \mathrm{deg}$ & $15 \mathrm{deg}$ & $45 \mathrm{deg}$ & $15 \mathrm{deg}$ & $45 \mathrm{deg}$ \\
\hline $\begin{array}{l}M^{*} \\
M_{D} \\
t \dagger \\
p\end{array}$ & $\begin{array}{c}-.57 \\
-.90^{\circ} \\
2.22 \\
>.01\end{array}$ & $\begin{array}{r}+.05 \\
+.14^{\circ} \\
.29 \\
>.01\end{array}$ & $\begin{array}{c}+.24 \\
+.38^{\circ} \\
.67 \\
>.01\end{array}$ & $\begin{array}{c}+1.07 \\
+3.21^{\circ} \\
7.73 \\
<.001\end{array}$ & $\begin{array}{l}-1.31 \\
-1.62^{\circ} \\
-3.58 \\
<.01\end{array}$ & $\begin{array}{l}-.75 \\
-2.37^{\circ} \\
-2.62 \\
>.01\end{array}$ & $\begin{array}{r}+3.67 \\
+5.05^{\circ} \\
4.43 \\
<.01\end{array}$ & $\begin{array}{r}+1.72 \\
+6.19^{\circ} \\
2.46 \\
>\quad .01\end{array}$ \\
\hline
\end{tabular}

* $M$ refers to mean in millimeters, $M_{D}$ to mean of angular conversions.

tTest of mean from zero, with $t(7)=3.50, p=.01$.

the three-way interaction were 0.86 and 0.001 , respectively.

To characterize the data further, single protected $t$ tests were carried out on each of the eight angular mean effects in Table 3 with a conservative critical value of $t(7)=3.50, p=.01$, to determine which means were different from zero. The results of these tests are shown in Table 3. Both of the obtuse-angle effects at $15^{\circ}$ were different from zero, but only one of the acute-angle effects, that for $45^{\circ}$ at the intersect end, was significant.

In order to compare our misalignments with those obtained by Day (1973), it was necessary to convert his mean errors and our uncorrected experimental condition errors to angular measures, because Day used uncorrected values and his separation between the test line and the near tip of the variable line was $30 \mathrm{~mm}$. The results of these conversions are shown in Table 4. Clearly, the effects at the common angle in both studies $\left(45^{\circ}\right)$ are very similar. In fact, so are those at the smaller angle, even though Day used a $\theta$ of $30^{\circ}$ while we used $15^{\circ}$.

It should be noted that Krantz and Weintraub (1973), using displays essentially similar to ours (upper dot only) with a $24.2^{\circ}$ transversal angle and a $20-\mathrm{mm}$ horizontal line-dot separation, obtained an obtuse-angle effect only slightly smaller than those in Table 4, namely $3.19^{\circ}$. However, their acute-angle effect was $-0.14^{\circ}$. We have no explanation for this discrepancy. In the absence of any angle (as in our control condition), Krantz and Weintraub obtained a positive effect $\left(+0.95^{\circ}\right)$, as we did.

\section{DISCUSSION}

The results of this experiment generally were consistent with those of Day (1973), obtained using the method of adjustment. When he used a forced-choice (staircase) technique, the acute-angle effect at $45^{\circ}$ reversed direction, an effect which he attributed to a tendency to judge the direction of misalignment of the two acute-angled "arrowheads" rather than the transversals considered alone. The present results provide indirect confirmation of Day's hypothesis: because we used only one acute angle, such arrowhead judgments could not have occurred and hence it would be expected that Day's adjustment method and our staircase method would yield similar results, as indeed they have done.

The data presented in this paper, however, provide even stronger evidence against the occurrence of any genuine and robust reversed or negative Poggendorff effect in acute-angled displays. First, for all dot-line separations, quite large misalignments in the Poggendorff direction (towards horizontal in this case) occurred both at the free end and at the intersect end of the test line when the inducing line was present (Table 2).

Similar directions of errors were obtained in the absence of the inducing line (Table 1; Figure 4), and the error magnitudes were entirely consistent with those reported by Wenderoth et al. (1978). Even when the experimental condition data were corrected by subtracting these control condition effects, a procedure not used by Restle (1969) or by Day (1973), none of the effects at the intersect end of the test line or at the free end was significantly in the direction opposite to the usual Poggendorff effect (Table 3).

On the contrary, at the intersect end of the test line, the corrected acute-angle effect for the $45^{\circ}$ display $\left(3.21^{\circ}\right)$ was significantly different from zero. Herein lies the single disagreement between Day's (1973) data and our results. Day found that the

Table 4

Comparison of Angular Misalignments Obtained by Day (1973) and the Present Study

\begin{tabular}{cccccc}
\hline & \multicolumn{2}{c}{ Day (1973) } & & \multicolumn{2}{c}{ Present Study } \\
\cline { 2 - 3 } \cline { 5 - 6 }$\theta$ & Obtuse & Acute & & Obtuse & Acute \\
\hline 15 & & & & 4.83 & 1.17 \\
30 & 4.56 & 1.54 & & \\
45 & 8.84 & 4.56 & & 7.54 & 5.39 \\
\hline
\end{tabular}

Note-All values given in degrees. 
acute-angle effect at $45^{\circ}$ and the parallelless effect (essentially equivalent to our control condition) were identical. Since our $+3.21^{\circ}$ effect represents the difference between the effect with and without the inducing line, we disagree: at least for the $45^{\circ}$ acuteangle display, there is a significant effect induced by the acute angle, over and above the effect that occurs in the absence of an angle.

These data are consistent with previous studies which have found that the illusion obtained with the complete Poggendorff figure is only slightly attenuated, if at all, in the obtuse-angle version. Using the complete display shown in Figure 1, Wenderoth et al. (1978) obtained an experimental-minus-control error of $6.45^{\circ}$ at the intersect end with a $45^{\circ}$ transversal, and the obtuse-angle effect at $45^{\circ}$ in the present study was $6.82^{\circ}$. The acute-angle effect, although not negative, was smaller, especially with the $15^{\circ}$ transversal.

One component of the illusion might be the angular displacement of part or all of the transversal away from the inducing line (i.e., acute-angle expansion). If other factors contribute to the effect at the intersect end (e.g., some kind of "mistracking"), then only at the free end would one measure a pure angular effect. One way of testing this hypothesis would be to vary the angle of the transversal: while the full Poggendorff illusion is larger, in angular terms, with a $45^{\circ}$ transversal than with a $15^{\circ}$ transversal (see Hotopf, Ollerearnshaw, \& Brown, 1974, Figure 10), the tilt illusion is larger at $15^{\circ}$ than at $45^{\circ}$ (Carpenter \& Blakemore, 1973; O'Toole \& Wenderoth, 1977). The data in Table 3 for the acuteangle display are consistent with this prediction. At the intersect end, the effects were both in the direction which would be predicted if dot alignment errors correlated with perceived test line orientation and if the line was displaced in orientation away from the inducing line, that is, towards horizontal. The large and significant $45^{\circ}$ effect $\left(3.21^{\circ}\right)$ exceeded the nonsignificant $15^{\circ}$ effect $\left(0.38^{\circ}\right)$. However, at the free end, although neither error was significant, the $15^{\circ}$ error was in the direction of horizontal $\left(0.90^{\circ}\right)$, and this was true for six of the eight subjects. At $45^{\circ}$, the mean error was slight and in the opposite direction $\left(0.14^{\circ}\right)$; exactly half of the subjects obtained effects in one direction, half in the other. We have since obtained other data consistent with this finding of larger effects at the free end with a $15^{\circ}$ than with a $45^{\circ}$ transversal (Wenderoth, White, \& Beh, Note 2).

Unfortunately, the obtuse-angle data in Table 3 give pause to any easy acceptance of the foregoing account, for in that case, at the free end, errors were larger at $45^{\circ}\left(2.37^{\circ}\right)$ than at $15^{\circ}\left(1.62^{\circ}\right)$, although only the $15^{\circ}$ mean was significant (Table 3). However, the present experiment was not designed mainly to test such differences. This is a between-subjects' effect with only eight subjects per group, and, in fact, when the data for the two groups are combined, exactly half of the subjects in each group lie above or below the median error. It is therefore doubtful whether this apparent difference is real, but further experiments would be required to establish whether there is a difference. Either way, the relatively large errors in these groups at the free end require explanation.

One possibility which we considered was something akin to Pressey's "attentive field" notion (Pressey, 1972): Dots may be displaced perceptually in the direction of the greatest density of lines in a figure. At the intersect end, this would predict that dots would appear too high in the obtuse-angle figures (attracted up in the direction of the obtuse-angle arm), thus increasing the illusion, but that dots would appear too low in the acute-angle figures, thus decreasing the illusion. This account is inadequate, however, because such a mechanism would enhance errors in the direction of horizontal at the free end of acute-angle figures and detract from such errors at the free end of obtuse-angle figures, predicting the opposite results to those at the free end in Table 5.

Whatever the nature of the effects which we have reported here, they are not whole-line effects, because identical but directionally opposite errors were not obtained at the two ends of the test line. Shortening the test line to $12^{\prime}$ or so does not equate these errors either, for, in the full display of Figure 1, such length reduction merely increments the error at each end by a constant amount (Wenderoth et al., 1978).

There is a great deal of evidence, discussed by Wenderoth et al. (1978), that line analyzers in the visual system are short, of the order of $9^{\prime}$ arc in length. It is possible therefore that, whatever effects are induced at the intersect end of the test line, they are weakened at the free end by averaging over less-affected analyzers along the total $2^{\circ} 6^{\prime}$ test line length. Whether this kind of explanation is tenable or not, it does not bear upon the mechanism which accounts for the greater obtuse- than acute-angle effects.

In conclusion, this experiment has provided additional, albeit indirect, evidence in support of Day's (1973) claim that the reversed Poggendorff effect with acute-angle figures is an artifact of the display which opposes arrowheads. In most respects, our results agree well with Day's. However, additional experiments are required to explain the differences obtained with acute- and obtuse-angle figures, not only at the intersect end of the lines, but also at the free end. 


\section{REFERENCE NOTES}

1. Wenderoth, P., White, D., \& Beh, H. The effects of peripheral and central fixation on a Poggendorff-type vernier alignment task. Manuscript submitted for publication, 1977.

2. Wenderoth, P., White, D., \& Beh, H. Dot alignments to one line in the presence of another: The effects of test line length, orientation and position. Manuscript submitted for publication, 1978.

\section{REFERENCES}

Bouma, H., \& Andriessen, J. J. Perceived orientation of isolated line segments. Vision Research, 1968, 8, 493-507.

Bouma, H., \& ANDRIEssen, J. J. Induced changes in the perceived orientation of line segments. Vision Research, 1970, 10, 333-349.

Carpenter, R. H. S., \& Blakemore, C. Interactions between orientations in human vision. Experimental Brain Research, 1973, 18, 287-303.

Cornsweet, T. N. The staircase method in psychophysics. American Journal of Psychology, 1962, 75, 485-491.

Curthoys, I., Wenderoth, P., \& Harris, J. The effects of the motion path and the length of the variable segment in the Poggendorff illusion without parallels. Perception \& Psychophysics, 1975, 17, 358-362.

DAY, R. H. The Poggendorff illusion with obtuse and acute angles. Perception \& Psychophysics, 1973, 14, 590-596.

DAY, R. H., \& Dickinson, R. G. The components of the Poggendorff illusion. British Journal of Psychology, 1976, 67, 537-552.

Hotopf, W. H. N., \& Ollerearnshaw, C. The regression to right angles tendency and the Poggendorff illusion. I. British Journal of Psychology, 1972, 63, 359-367. (a)

Hotopf, W. H. M., \& Ollerearnshaw, C. The regression to right angles tendency and the Poggendorff illusion. II. British Journal of Psychology, 1972, 63, 369-379. (b)

Hotopf, W. H. N., Ollerearnshaw, C., \& Brown, S. The regression to right angles tendency and the Poggendorff illusion. III. British Journal of Psychology, 1974, 65, 213-231.

KRANTZ, D. H., \& Weintraub, D. J. Factors affecting perceived orientation of the Poggendorff transversal. Perception \& Psychophysics, 1973, 14, 511-517.

Matin, E. Light adaptation and the dynamics of induced tilt. Vision Research, 1974, 14, 255-265.

Matin, L. Eye movements and perceived visual direction. In D. Jameson \& L. M. Murvich (Eds.), Handbook of sensory physiology VII/4: Visual psychophysics. Berlin: Springer, 1972.

O'Toole, B., \& Wenderoth, P. The tilt illusion: Repulsion and attraction effects in the oblique meridian. Vision Research, 1977, 17, 367-374.

Pressey, A. W. The assimilation theory of geometrical illusions: An additional postulate. Perception \& Psychophysics, 1972, 11, 28-30.

Prytulak, L. S. The effect of fixation point on the appearance of rectilinearity. Perception \& Psychophysics, 1973, 14, 387-393. (a)

Prytulak, L. S. Interaction of fixation point and stimulus orientation on the appearance of rectilinearity. Perception \& Psychophysics, 1973, 14, 493-496. (b)

Restle, F. Illusions of a bent line. Perception \& Psychophysics, 1969, 5, 273-274.

RoDGER, R. S. Intermediate statistics. Sydney: University Co-operative Bookshop, 1965.

Tong, L., \& Weintraub, D. J. Contour displacements and tracking errors: Probing twixt Poggendorff parallels. Perception \& Psychophysics, 1974, 15, 258-268.

Weintraub, D. J., \& Krantz, D. H. The Poggendorff illusion: Amputations, rotations and other perturbations. Perception \& Psychophysics, 1971, 10, 257-264.

Wenderoth, P., Beh, H., \& White, D. Perceptual distortion of an oblique line in the presence of an abutting vertical line. Vision Research, 1978, in press.

Wetherill, G. B., \& LevitT, H. Sequential estimation of points on a psychometric function. British Journal of Mathematical \& Statistical Psychology, 1965, 18, 1-10.

WINER, N. J. Statistical principles in experimental design. New York: McGraw-Hill, 1962.

(Received for publication July 15, 1977; revision accepted February 17, 1978.) 